\title{
An overview of angiotensin- converting enzyme inhibitors in the treatment of hypertension
}

MICHAEL A. WEBER, M.D.

Long Beach, California

Two angiotensin

converting enzyme inhibitors are available for the treatment of hypertension. As a class, the converting enzyme inhibitors exhibit antihypertensive efficacy equivalent to that found with other types of agents. Early studies with the first of these, captopril, demonstrated its effectiveness for treatment-resistant hypertension; later work has affirmed its efficacy as monotherapy and its relative freedom from symptomatic adverse effects, thus establishing captopril as appropriate first-line therapy for hypertension of all degrees of severity in patients with normal renal function. Enalapril, the second converting enzyme inhibitor, has been approved recently for the treatment of hypertension, and its efficacy and clinical characteristics appear to be similar to those of captopril. In controlled clinical trials, direct comparisons with beta-blocker or diuretic therapy have shown captopril to be equally effective in reducing blood pressure while producing fewer symptomatic or metabolic side effects. In mild to moderate essential hypertension, captopril is effective when administered twice daily in doses of 25 or $50 \mathrm{mg}$; higher doses usually do not increase its blood pressure-lowering effects. The combination of captopril with a diuretic in low doses has been shown to be especially effective. In further studies, once-daily doses of the drug have been found to be clinically effective, although the use of this regimen has not yet been formally affirmed. In lower doses, captopril may be less effective in black patients than in white patients, but black patients appear to respond well if their doses are increased. Antihypertensive effects in elderly patients during captopril treatment are equivalent to those in younger patients. Therapy with angiotensin-converting enzyme inhibitors appears to have broad utility and a favorable side effects profile in the treatment of essential hypertension.
Clinical experience with the first angiotensinconverting enzyme (ACE) inhibitor, captopril, initially focused on patients with severe and complicated forms of hypertension. Its mechanism of action differed from other antihypertensive agents, and captopril was used chiefly in patients whose high blood pressure had been unresponsive to ongoing treatment. More recently, attention has turned to the use of ACE inhibitors in patients with mild to moderate hypertension, primarily because of their favorable side effects profile. ACE inhibitors afford the opportunity of treating high blood pressure without introducing the adverse effects traditionally associated with antihypertensive therapy.

Mechanism of action

ACE inhibitors were developed to block the effects of the renin-angiotensin-aldosterone (RAA) system. Renin, an enzyme released from the kidney, works on a substrate, angiotensinogen, to produce angiotensin I. This substance, in turn, is acted upon by a converting enzyme to produce angiotensin II, which has a powerful direct vasoconstrictor effect on the arterial circulation. Angiotensin II also stimulates the production of aldosterone from the adrenal cortex, which promotes sodium and water retention. Both of these actions raise blood pressure. ACE inhibitors prevent the conversion of angiotensin I into angiotensin II, thereby interrupting the system.

A second mechanism also may be involved, according to Zusman and coauthors. ${ }^{1}$ The converting enzyme known as kininase II is responsible also for the degradation of the vasodilatory substance bra- 
dykinin. Thus, ACE inhibitors could lower blood pressure partly by increasing plasma concentrations of kinin. A secondary action of the kinins, the stimulation of intrarenal prostaglandins, could contribute meaningfully to the antihypertensive effects. The potential importance of the kinin-prostaglandin mechanism has been the subject of studies in which captopril has been shown to lower blood pressure by actions clearly separate from inhibition of angiotensin II generation. Interestingly, this property appears to be confined to ACE inhibitors, such as captopril, that contain a sulfhydryl bridge in their molecular structure. Therefore, enalapril and other ACE inhibitors now being evaluated do not appear to have the ability to stimulate prostaglandin production.

\section{Clinical experience: Moderate and severe hypertension}

Increased activity of the RAA system had been linked to severe hypertension, and, when first studied, captopril was used in patients whose high blood pressure had not responded adequately to a regimen of standard triple therapy with a diuretic, a beta-blocker, and a vasodilator. Added to this threedrug regimen, captopril further reduced blood pressure. ${ }^{2}$

When the previous triple-therapy agents were discontinued in this early study, ${ }^{2}$ captopril was found to be as effective as the previous agents had been in combination.

Long-term multicenter experience with captopril monotherapy or combination captopril/diuretic therapy in several thousand patients with moderate to severe hypertension was summarized by Jenkins and coauthors (Fig. 1). ${ }^{3}$ These data indicate that captopril is effective in these patients and that, overall, there is no evidence for tolerance to its antihypertensive action. The average dose of captopril administered to these patients was slightly above $150 \mathrm{mg}$. daily, thus suggesting that most individuals should receive treatment in the range of $50 \mathrm{mg}$. 3 times daily. Recent experience ${ }^{4}$ with patients with diastolic blood pressure in the 95-115 $\mathrm{mm}$. $\mathrm{Hg}$ range indicates that lower doses and twice daily dosing can be equally effective. In this study, 50 or $100 \mathrm{mg}$. of captopril taken two times a day produced highly satisfactory results; in some white patients, twice-daily doses of $25 \mathrm{mg}$. were effective.

\section{Clinical experience: Mild to moderate hypertension}

It has been common practice to treat mild or moderate essential hypertension with a stepped approach. Diuretic agents usually have been the first step in this systematic therapeutic method, but the

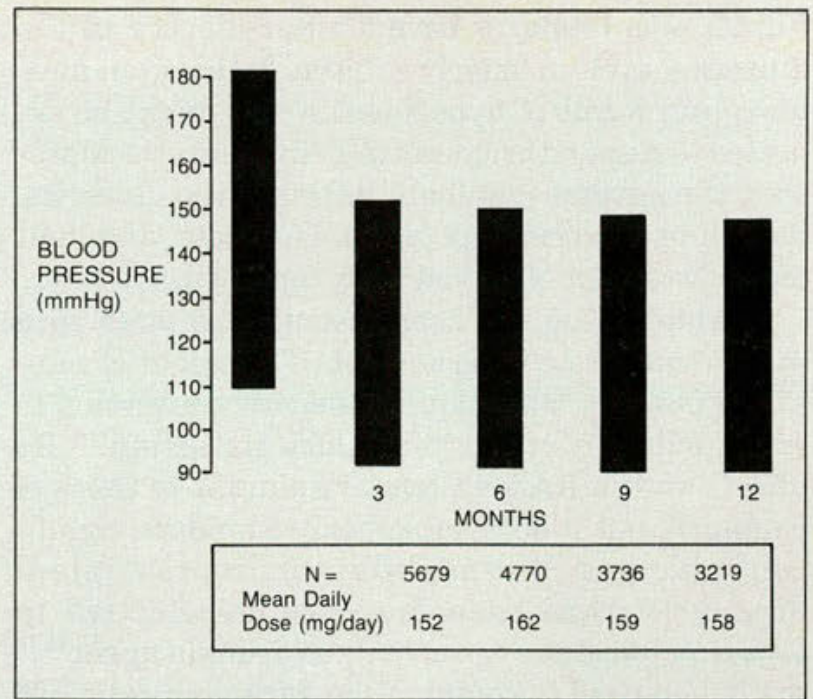

Fig. 1. Average blood pressure measurements in patients with moderate to severe hypertension following treatment with captopril alone or in combination with a diuretic (data from Jenkins and coathors $\left.{ }^{3}\right) . N$ indicates the number of patients available for analysis at the various stages of this ongoing study.

most recent recommendation of the Joint National Committee on Detection, Evaluation and Treatment of High Blood Pressure ${ }^{5}$ has supported the growing practice of using beta-blocking agents or other alternatives as initial therapy. If captopril is to be considered as first-line monotherapy for the treatment of milder forms of hypertension, it is relevant to examine studies in which it has been compared directly with other well-established approaches.

Captopril was compared with propranolol in a double-blind study 6 of patients with mild to moderate hypertension. A total of 167 patients were randomized to receive propranolol in doses titrated to achieve optimal antihypertensive effects, and 157 were titrated with captopril. Each drug reduced blood pressure, although there was a slight but statistically significant tendency for captopril to have a more powerful antihypertensive effect. Of greater clinical importance, perhaps, were the side effect experiences reported with the two drugs. Of the patients receiving propranolol, 26 (15.6 percent) reported symptomatic side effects, a frequency similar to that reported for most other commonly used antihypertensive agents. ${ }^{7}$ Only 6 of the patients (3.8 percent) receiving captopril complained of adverse effects. Overall, 7 patients receiving propranolol discontinued treatment because of side effects, as did 2 patients taking captopril.

Captopril also has been compared with hydrochlorothiazide $^{8}$ and chlorthalidone. ${ }^{9}$ The ACE in- 
hibitor was found to have similar efficacy to the diuretics, even in elderly subjects, ${ }^{9}$ who often have low-renin forms of hypertension and might be expected to respond preferentially to a diuretic. Moreover, the adverse metabolic effects of the diuretics, including changes in potassium, glucose, and lipid levels, were not observed with captopril.

Enalapril also has been tested in patients with mild to moderate hypertension. This agent is actually a prodrug, and requires hepatic conversion to enalaprilat in order to produce its action. ${ }^{10}$ Its effects on the RAA system are similar to those of captopril, but it does not appear to produce significant changes in bradykinin or in prostaglandins. ${ }^{11-13}$ It has been found to be effective in lowering blood pressure, both as a single agent ${ }^{14-16}$ and when used in combination with a diuretic. ${ }^{17,18}$

\section{Dosing studies: Mild \\ to moderate hypertension}

Extensive experience with captopril in patients with mild to moderate hypertension has come from the Veterans Administration Cooperative Study Group on Antihypertensive Agents. ${ }^{19}$ Almost 500 hypertensive men were randomized into four different treatment groups and one placebo group. These investigators found that even very low doses of captopril were highly effective in reducing high blood pressure when the drug was administered three times daily; in fact, doses as low as $12.5 \mathrm{mg}$. three times a day were as effective as thrice-daily $50 \mathrm{mg}$. doses.

After completing a 7-week phase of monotherapy,

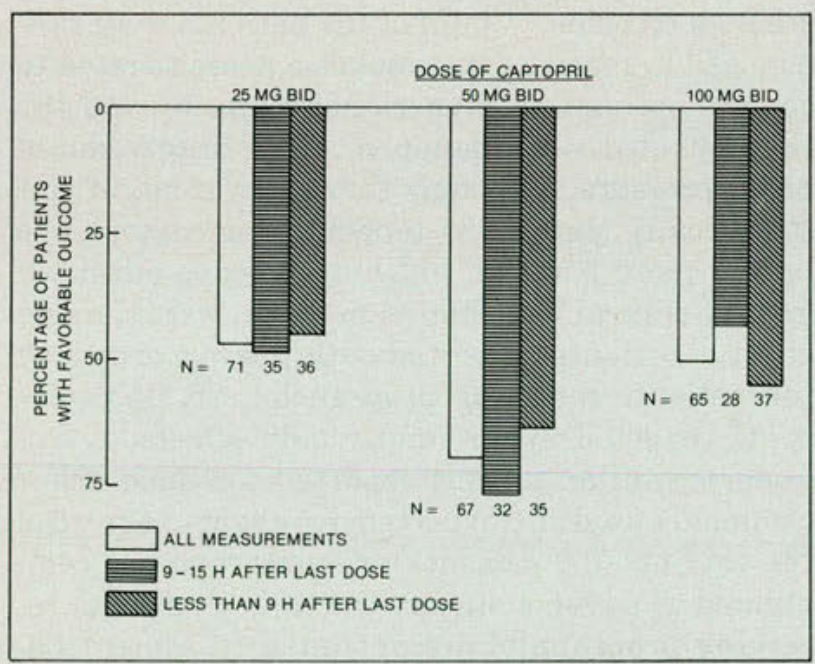

Fig. 2. Percentages of patients exhibiting favorable referrals (decrease in diastolic blood pressure to $<90 \mathrm{~mm}$. Hg or a fall of at least $10 \mathrm{~mm} . \mathrm{Hg}$ ) as measured at different times after the most recent dose during captopril therapy (data from Drayer and Weber ${ }^{4}$. all placebo subjects and two-thirds of treated patients were given $25 \mathrm{mg}$. of hydrochlorothiazide twice daily in addition to their ongoing treatment for an additional 7 weeks. For both the placebo subjects and the captopril-treated patients, the addition of the diuretic produced marked additional decrements in blood pressure. Indeed, the average blood pressures in the patients receiving the combination regimen were dramatically lower than pretreatment levels, and pressure levels were completely normalized in the majority of patients. As in the monotherapy phase, there were significant differences among the captopril-treated patient groups, indicating that the lowest dose of captopril used was as effective as the highest dose. Also, the twice-daily regimen was as effective as the thricedaily regimen.

Subgroups of patients participating in this cooperative study were continued on their treatment, either with captopril alone or a captopril-hydrochlorothiazide combination, for additional treatment periods of approximately 10 months. There were no significant differences between the blood pressures measured after the initial treatment periods and those measured after several additional months of the same therapy. Thus, it was concluded that the antihypertensive efficacy of these regimens could be sustained on a long-term basis.

\section{Frequency of administration studies}

In a 1983 multicenter trial conducted by Drayer and Weber, ${ }^{4}$ whether captopril could be effective when administered twice daily also was studied. The 294 patients in this study, all of whom had mild to moderate essential hypertension, were randomized into four groups and received placebo twice daily or captopril in doses of $25 \mathrm{mg}$., $50 \mathrm{mg}$., or $100 \mathrm{mg}$. twice daily. At the lowest dose, $25 \mathrm{mg}$. twice daily, captopril was superior to placebo. A dose of 50 $\mathrm{mg}$. of captopril two times a day, however, was significantly more effective. Notably, the maximum dose of $100 \mathrm{mg}$. twice daily was no more effective than $50 \mathrm{mg}$. twice a day. These findings seem to confirm the relatively flat clinical dose-response curve for captopril when used in mild to moderate essential hypertension, and suggest that twicedaily doses of either $25 \mathrm{mg}$. or $50 \mathrm{mg}$. should constitute the usual approach for most patients with this form and degree of hypertension.

A closer look at the duration of action is shown in Figure $2 .{ }^{4}$ Blood pressures were measured at different times relative to the last dosage of active medication. In this manner, it was possible to compare blood pressures measured less than 9 hours after the last dose of captopril with blood pressures measured between 9 and 15 hours after the last 
dose. There was no significant difference between the blood pressures for these two time periods, indicating that the duration of action of captopril is sufficient to ensure its efficacy as a twice-daily antihypertensive medication.

Inevitably, there has been interest in the possibility that captopril might be effective when given on a once-daily basis. This hypothesis was first evaluated by Reyes and associates ${ }^{20}$ in a small number of patients with moderate to severe hypertension (an average baseline blood pressure of approximately $210 / 130 \mathrm{~mm}$. $\mathrm{Hg}$ ). All patients received captopril monotherapy in a fixed dose of $100 \mathrm{mg}$. daily. Blood pressure measurements, which were obtained 24 hours after the most recent dose of captopril had been administered, were lower after 2 weeks of treatment and continued to fall during a further 6 weeks. Although blood pressure was not completely lowered into the normal range, these data indicated a useful degree of antihypertensive action of captopril in a single daily dose.

Subsequently, a multicenter study ${ }^{21}$ was conducted for four randomized treatment groupsplacebo once daily, $100 \mathrm{mg}$. captopril once daily, 100 mg. captopril twice daily, and $100 \mathrm{mg}$. captopril combined with $25 \mathrm{mg}$. hydrochlorothiazide once daily. Once-daily captopril monotherapy was found to lower blood pressure to a significantly greater extent than placebo. There was a modest further increase in efficacy when captopril was given twice daily, and yet better efficacy when captopril was combined with a diuretic, even on a once-daily basis. These results confirmed Reyes and associates' 20 findings and suggest that once-daily monotherapy with captoril can be an effective approach in patients with mild to moderate hypertension.

Like captopril, the duration of action of enalapril is also dose-related. ${ }^{10}$ Thus, while most reports of the efficacy of enalapril have been based on twicedaily administration, administration once a day can be effective when higher doses are used..$^{15,22} \mathrm{~A}$ review ${ }^{10}$ of experiences with enalapril has led to the recommendation that a starting dose of $5 \mathrm{mg}$. twice daily be employed; if necessary, the dosage can be increased to a maximum of $20 \mathrm{mg}$. twice daily, or the entire dosage can be administered once daily. A recent comparative study ${ }^{23}$ has shown that enalapril and captopril have similar efficacy when given once daily in patients with mild to moderate hypertension. Comparative doses of captopril and enalapril are summarized in Table 1.

It should be emphasized that the antihypertensive efficacy of captopril and enalapril can be enhanced markedly by the addition of a diuretic. In some patients who already are established on diuretic treatment, the addition of an ACE inhibitor occasionally can produce a marked and rapid reduction in blood pressure. Therefore, it has been recommended that blood pressures be monitored following the first dose of the ACE inhibitor in patients receiving other antihypertensive therapy. Alternatively, the first dose of the ACE inhibitor can be given immediately before retiring at night so as to prevent any symptomatic consequences of an excessive blood pressure response.

\section{Demographic factors}

The large multicenter study ${ }^{4}$ of twice-daily captopril administration provided an excellent opportunity for assessing response to treatment on a demographic basis. The percentage of patients from differing subgroups with favorable outcomes of treatment (diastolic blood pressure decreased to $<90 \mathrm{~mm}$. $\mathrm{Hg}$ or a fall of at least $10 \mathrm{~mm}$. Hg) are shown in Figure 3 for two main treatment groups (captopril $25 \mathrm{mg}$. twice daily or $50 \mathrm{mg}$. twice daily). With the lower dose, white patients had a response rate greater than black patients. This difference,

\begin{tabular}{|c|c|c|}
\hline Type of dose & Captopril & Enalapril \\
\hline Suggested starting dose* & $\begin{array}{l}25 \text { mg. twice } \\
\text { a day }\end{array}$ & $5 \mathrm{mg}$. twice a day \\
\hline Usual range $\dagger^{\dagger}$ & $\begin{array}{l}25-50 \mathrm{mg} \text {. twice } \\
\text { a day }\end{array}$ & $\begin{array}{l}5-20 \mathrm{mg} \text {. twice } \\
\text { a day }\end{array}$ \\
\hline Once-daily dosing $\ddagger$ & $50-100 \mathrm{mg}$ & $10-40 \mathrm{mg}$ \\
\hline \multicolumn{3}{|c|}{$\begin{array}{l}\text { *Initial doses should be halved if these agents are added to other anti- } \\
\text { hypertensive therapy. Lower doses are recommended for patients with } \\
\text { congestive heart failure or impaired renal function. }\end{array}$} \\
\hline \multicolumn{3}{|c|}{$\begin{array}{l}\text { tHigher does (up to } 450 \mathrm{mg} \text {. daily) of captopril may be used, but such } \\
\text { dosages are unlikely to provide much further efficacy. }\end{array}$} \\
\hline \multicolumn{3}{|c|}{$\begin{array}{l}\ddagger \text { Preliminary data-approved for enalapril but not yet formally ap- } \\
\text { proved for captopril. }\end{array}$} \\
\hline
\end{tabular}

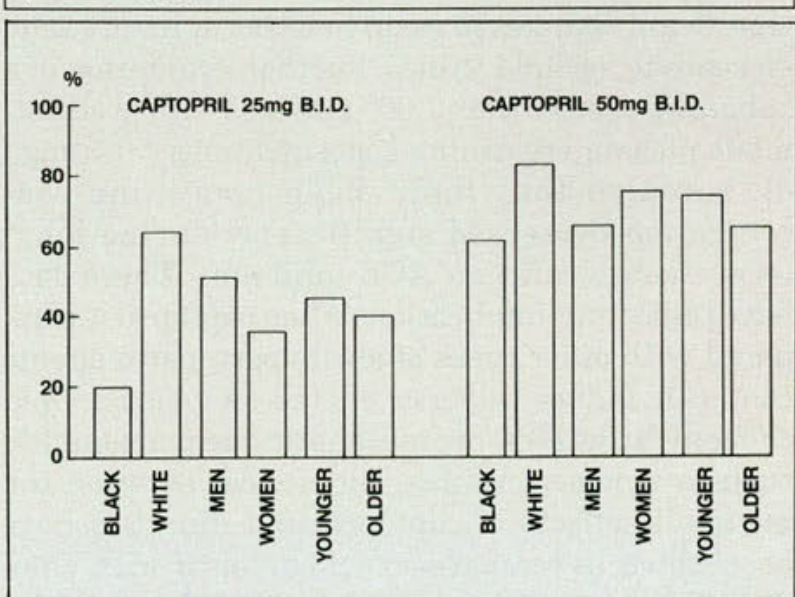

Fig. 3. Percentages of subgroups of hypertensive patients exhibiting favorable responses (decrease in diastolic blood pressure to $<90 \mathrm{~mm} . \mathrm{Hg}$, or a fall of at least $10 \mathrm{~mm} . \mathrm{Hg}$ ) during treatment with captopril (data from Drayer and Weber ${ }^{4}$ ). 
however, might simply reflect a differing sensitivity to dosage, for when captopril was administered as $50 \mathrm{mg}$. twice a day, the difference between the two patient groups was far less. This dependence of black patients on a slightly higher dose might reflect a more rapid metabolism of the drug, or, perhaps, a differing underlying mechanism for the hypertension that requires a higher concentration of drug. Nevertheless, in a dose of 50 $\mathrm{mg}$. twice daily, approximately 60 percent of black patients responded satisfactorily to captopril monotherapy. There were no significant differences between men and women, or between younger (less than 55 years) and older patients. In either dosage category, these findings suggest that captopril may not be as much influenced by demographic differences as other commonly used antihypertensive agents. For example, beta-blockers tend to be more effective in white than in black patients, whereas diuretic agents appear to be more effective in black than in white patients. ${ }^{24}$ And there is evidence that calcium channel blockers might have greater antihypertensive efficacy in elderly individuals, while beta-blockers might work better in the young. ${ }^{25}$

\section{Side effects}

\section{Symptomatic effects}

ACE inhibitors are relatively free of the symptomatic complaints that typify other types of antihypertensive therapies. This issue is considered in depth elsewhere in this issue.

\section{Metabolic effects}

Captopril does not appear to produce significant alterations in routinely obtained plasma biochemistry profiles. In a prospective surveillance study of several thousand patients, ${ }^{26}$ treatment with this agent for up to three years did not produce significant changes in renal function or in uric acid, electrolyte, or lipid values. Further, evaluation of a subgroup of more than 1,000 patients with pretreatment plasma creatinine concentrations $>1.5 \mathrm{mg}$./ dl. revealed that their mean creatinine concentration decreased significantly during longterm therapy with an ACE inhibitor. ${ }^{3}$ These data have important implications when captopril is compared with other types of antihypertensive agents that can induce adverse effects on plasma lipid concentrations or on metabolic measurements, such as uric acid values. Differences between the metabolic effects of captopril and diuretics have been noted in comparisons of captopril with chlorothalidone ${ }^{9}$ or hydrochlorothiazide. ${ }^{8}$ The diuretics can cause hypokalemia and other well-documented adverse changes. Actually, captopril might attenuate the severity of some of the unwanted bio- chemical effects of diuretic therapy, including those on potassium, glucose, and uric acid values,${ }^{8}$ which would further enhance the value of the efficacious captopril-diuretic combination.

It has been suggested that administration of captopril concurrently with food may decrease absorption of the drug. In a recent study, ${ }^{27}$ however, captopril was found to be equally effective in lowering blood pressure whether administered at a meal or to fasting patients.

\section{Conclusion}

The converting enzyme inhibitors have now been found to be an effective and well-tolerated form of treatment in patients with hypertension of all degrees of severity. They are usually given twice daily, although there is now growing evidence of efficacy when used just once a day. Because they do not produce adverse metabolic effects, it appears to be a particularly appropriate for long-term therapy. 1. Zusman, R.M., et al.: Renin and non-renin-mediated antihypertensive
actions of converting enzyme inhibitors. Kidney Int 25:969-83, 1984
2. Drayer, J.I.M., et al.: Differential effects of diuresis and beta-adre-
noreceptor blockade during angiotensin-converting enzyme inhibition in
patients with severe hypertension. J Clin Pharmacol $22: 179-86$, Apr 82
3. Jenkins, A.C., et al.: Captopril in hypertension. Seven years later. J
Cardiovasc Pharmacol 7:S96-S101, 1985

4. Drayer, J.I.M., and Weber, M.A.: Monotherapy of essential hypertension with a converting enzyme inhibitor. Hypertension 5(SIII):108-13, Sep-Oct 83

5. Joint National Committee on Detection, Evaluation and Treatment of High Blood Pressure. The 1984 report. JAOA 83:642-59, May 84

6. Kaneko, Y., et al.: Antihypertensive effect of low dose captopril in mild to moderate essential hypertension. Abstract 211. Proceedings of the 9th International Society on Hypertension, 1982

7. McMahon, F.G.: Management of essential hypertension. The new low dose era. Futura Publishing Company, Inc., New York, 1984

8. Weinberger, M.H.: Blood pressure and metabolic responses to hydrochlorothiazide, captopril, and the combination in black and white mildto-moderate hypertensive patients. J Cardiovasc Pharmacol 7:S52-5, 1985

9. Corea, L., et al.: Converting enzyme inhibition vs. diuretic therapy as first therapeutic approach to the elderly hypertensive patient. Curr Ther Research 36:347-51, Aug 84

10. Riley, L.J., Vlasses, P.H., and Ferguson, R.K.: Clinical pharmacology and therapeutic applications of the new oral converting enzyme inhibitor, enalapril. Am Heart J 109:1085-9, May 85

11. Ulm, E.H.: Enalapril maleate (MK421), a potent, nonsulfhydryl angiotensin-converting enzyme inhibitor. Absorption, disposition, and metabolism in man. Drug Metab Rev 14:99-110, 1983

12. Odya, C.E., et al.: Immunoreactive bradykinin and (des-Arg ${ }^{9}$ )-bradykinin in low-renin essential hypertension-before and after treatment with enalapril (MK421). J Lab Clin Med 102:714-21, Nov 83

13. Vlasses, P.H., et al.: Urinary excretion of prostacyclin and thromboxane $A_{2}$ metabolites after angiotensin converting enzyme inhibition in hypertensive patients. Prostaglandins Leukotrienes Med 11:143-50, 1983 14. Millar, J.A., et al.: Pharmacodynamics of converting enzyme inhibition. The cardiovascular, endocrine and autonomic effects of MK421 (enalapril) and MK521. Br J Clin Pharmacol 14:347-55, 1982

15. Gavras, H., et al.: Effects of the new oral angiotensin converting enzyme inhibitor MK-421 in human hypertension. Clin Exp Hypertens 4:303-14, 1982

16. Hodsman, G.P., et al.: Enalapril in the treatment of hypertension with renal artery stenosis. Br Med J 287:1413-7, 12 Nov 83 
17. Vlasses, P.H., et al.: Comparative antihypertensive effects of enalapril maleate and hydrochlorothiazide, alone and in combination. J Clin Pharmacol 23:227-33, May-Jun 83

18. Ferguson, R.K., et al.: Effects of enalapril, a new converting enzyme inhibitor in hypertension. Clin Pharmacol Ther 32:48-53, Jul 82

19. Veterans Administration Cooperative Study Group on Antihypertensive Agents: Low-dose captopril for the treatment of mild to moderate hypertension. I. Results of a 14-week trial. Arch Intern Med 144:1947-53, Oct 84

20. Reyes, A.J., Leary, W.P., and Acosta-Barrios, T.N.: Once-daily administration of captopril and hypotensive effect. J Cardiovasc Pharmacol 7:S16-9, 1985

21. Schoenberger, J.A.: Once daily treatment of essential hypertension with captopril. Proceedings of the Second European Meeting on Hypertension, Milan, 1985

22. Kono, T., et al.: Effects of a new angiotensin-converting enzyme inhibitor, MK421, in normal men and patients. Endocrinol Jpn 29:615-22, Oct 82

23. Garanin, G.: A comparison of once-daily antihypertensive therapy with captopril and enalapril. Curr Ther Res 40:567-75, Sep 86
24. Hollifield, J.W., Sherman, K., and Slaton, P.: Age, race and sex as a determinant of successful antihypertensive therapy. Prev Med 7:88, 1978 25. Buhler, F.R., et al.: Renin profiling to select antihypertensive baseline drugs. Renin inhibitors for high-renin and calcium entry blockers for low-renin patients. Am J Med 77:36-42, 20 Aug 84

26. Groel, J.T., et al.: Long-term antihypertensive therapy with captopril. Hypertension 5 (SIII):145-51, Sep-Oct 83

27. Salvetti, A., et al.: Influence of food on acute and chronic effects of captopril in essential hypertensive patients. J Cardiovasc Pharmacol 7:S25-9, 1985

Dr. Weber is chief of the Section of Hypertension, Veterans Administration Medical Center, Long Beach, California, and professor of medicine, University of California, Irvine.

Dr. Weber, Veterans Administration Medical Center, 5901 East 7th Street, Long Beach, California 90822. 